
хронической сердечной недостаточностью

\author{
Шлевков Н.Б. • Гаспарян А.Ж. • Жамбеев А.А. ' • Салами Х.Ф. ${ }^{1}$ • Гусева Е.В.' • Тарасовский Г.С. ${ }^{1}$ •

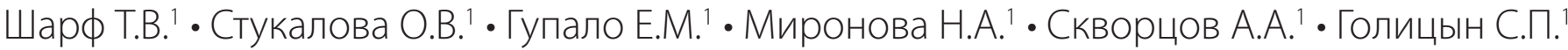

Обоснование. По данным многочисленных исследований, от 30 до $50 \%$ пациентов с хронической сердечной недостаточностью (ХCH) оказываются невосприимчивы к применению сердечной ресинхронизирующей терапии (СРТ) и модуляции сердечной сократимости (МСС), несмотря на тщательный отбор больных в соответствии с существующими рекомендациями. Представляет интерес изучение нейрогормонов, отражающих процессы напряжения (NT-proBNP) и фиброза (sST2) миокарда, в качестве возможных дополнительных маркеров ответа больных XCH на применение устройств СРТ и МСС.

Цель - изучить возможности использования у пациентов с XCH биомаркеров NT-proBNP и sST2 в комбинации с параметрами трансторакальной эхокардиографии (ЭхоКГ) и магнитно-резонансной томографии (МРТ) сердца с контрастированием для прогнозирования положительного ответа на применение устройств СРТ и МСС.

Материал и методы. В исследование включен 51 пациент (41 мужчина, 10 женщин, средний возраст составил $58 \pm 12$ лет (от 26 до 79 лет)) с постинфарктным кардиосклерозом $(\mathrm{n}=22)$ или неишемической кардиомиопатией $(n=29)$, снижением фракции выброса левого желудочка менее 35\% и признаками XCH II-III функционального класса по NYHA, у которых в течение не менее 3 месяцев проводилась оптимальная медикаментозная терапия. Обследование пациентов включало проведение ЭхоКГ, МРТ сердца с контрастированием, а также определение значений биомаркеров NT-proBNP и SST2. По окончании обследования 39 больным были имплантированы СРТ, 12 - МСС. По результатам проспективного наблюдения на протяжении 18-24 месяцев с помощью методов однофакторного, многофакторного и ROCанализа проведен поиск предикторов ответа на применение каждого типа устройств.

Результаты. Признаки положительного ответа на применение СРТ-устройств с функцией дефибриллятора (СРТ-Д) регистрировались у 21 (54\%) пациента, на использование МСС у 7 (58\%) больных. По итогам многофакторного анализа, предикторами такого ответа на применение СРТ-Дбыли: 1) значение SST2 < 50 нг/мл, 2) значение NT-proBNP <3900 пг/мл, 3) наличие в левом желудочке менее 3 сегментов с фиброзом (по МРТ сердца) и 4) передне-задний размер левого предсердия < 4,8 см (по ЭхоКГ). Наличие 2 из 4 вышеперечисленных признаков позволяло прогнозировать положительный ответ на применение СРТ с точностью $87 \%$ (чувствительность 90\%, специфичность 83\%). Предикторами положительного ответа больных на применение МСС служили: 1) значение SST2<30 нг/мл, 2) конечно-диастолический размер левого желудочка $<78$ мм (по ЭхоКГ), 3) возраст <56 лет, 4) значение индекса массы тела $<27 \mathrm{kr} / \mathrm{M}^{2}$. Наличие 2 из 4 признаков позволяло прогнозировать положительный ответ на применение МСС с точностью $92 \%$ (чувствительность 86\%, специфичность 100\%).
Заключение. Единственным универсальным маркером отклика больных XСH со сниженной фракцией выброса левого желудочка на применение обоих типов устройств были исходные значения SST2 (<50 нг/мл для СРТ-Д и <30 нг/мл для МСС). Это указывает на потенциальную возможность повышения эффективности вышеописанных методов при их применении в более ранние сроки от дебюта заболевания, а также после достижения максимально возможной компенсации явлений XCH у данной категории пациентов.

Ключевые слова: биомаркеры, NT-proBNP, SST2, хроническая сердечная недостаточность, сердечная ресинхронизирующая терапия, модуляция сердечной сократимости, прогнозирование

Для цитирования: Шлевков НБ, Гаспарян АЖ, Жамбеев АА, Салами ХФ, Гусева ЕВ, Тарасовский ГС, Шарф ТВ, Стукалова ОВ, Гупало ЕМ, Миронова НА, СКворцов АА, Голицын СП. Растворимый рецептор подавления туморогенности второго типа (SST2) новый потенциальный биомаркер положительных результатов применения сердечной ресинхронизирующей терапии и модуляции сердечной сократимости у больных хронической сердечной недостаточностью. Альманах клинической медицины. 2021;49(2):99-112. doi: 10.18786/2072-05052021-49-025

Поступила 22.04.2021; доработана 27.04.2021; принята к публикации 30.04.2021; опубликована онлайн 26.05.2021 
$\mathrm{X}$ роническая сердечная недостаточность $(\mathrm{XCH})$ - одна из основных причин заболеваемости и смертности населения развитых стран мира [1]. Несмотря на заметные успехи лекарственной терапии $\mathrm{XCH}$ [1-4], значительная часть этих больных нуждается в дополнительном применении немедикаментозных методов лечения, среди которых важную роль играет имплантация устройств сердечной ресинхронизирующей терапии (СРТ) и модуляторов сердечной сократимости (МСС). Как показали многочисленные исследования, от 30 до 50\% пациентов с ХСН оказываются невосприимчивы к применению устройств СРТ и МСС [1, 5-7], даже после тщательного отбора таких больных в соответствии с существующими критериями. В последние годы активно исследуются структурные, электрофизиологические особенности больных ХCH, лежащие в основе их положительной реакции либо, напротив, резистентности к применению устройств СРТ [8-12]. А механизмы наличия или отсутствия положительной реакции миокарда больных ХCH на использование устройств МСС практически не изучены.

Современное ведение больных ХCH фактически немыслимо без регулярного контроля уровня нейрогормонов крови [13-15], из которых наиболее подробно исследован N-концевой фрагмент предшественника мозгового натрийуретического пептида (англ. N-terminal fragment of brain natriuretic peptide progenitor, NT-proBNP). Внимание ученых сосредоточено на растворимом рецепторе подавления туморогенности второго типа (англ. suppression of tumorigenicity 2, sST2) как дополнительного, а нередко и альтернативного биомаркера для оценки прогноза больных ХCH и мониторирования их состояния. В отличие от NT-proBNP, биомаркера напряжения миокарда предсердий и желудочков [13, 14], sST2 косвенно отражает эффективность работы кардиопротективной сигнальной системы организма, противостоящей процессам ремоделирования сердца [13-16].

Цель настоящего исследования - изучить возможности использования у пациентов с ХСН биомаркеров NT-proBNP и sST2 в комбинации с параметрами трансторакальной эхокардиографии (ЭхоКГ) и магнитно-резонансной томографии (МРТ) сердца с контрастированием для прогнозирования положительного ответа на применение устройств СРТ и МСС.

\section{Материал и методы}

Дизайн исследования

Проведено проспективное открытое клиническое исследование. Началом наблюдения за пациентами
Шлевков Николай Борисович - канд. мед. наук, вед. науч. сотр. лаборатории интервенционных методов диагностики и лечения нарушений ритма, проводимости сердца и синкопальных состояний отдела клинической электрофизиологии и рентгенохирургических методов лечения нарушений ритма сердца Научно-исследовательского института клинической кардиологии им. А.Л. Мясникова'; ORCID: https://orcid.org/0000-0003-3956-1860

$\triangle 121552$, г. Москва, ул. 3-я Черепковская, 15а, Российская Федерация. Тел.: +7 (495) 1504419. E-mail: nik.shlevkov@inbox.ru

Гаспарян Арменуи жораевна - аспирант отдела клинической электрофизиологии и рентгенохирургических методов лечения нарушений ритма сердца Научно-исследовательского института клинической кардиологии им. А.Л. Мясникова'; ORCID: https://orcid.org/0000-0001-9984-6505.

E-mail: doctor_gasparyan@inbox.ru

Жамбеев Азамат Амурбиевич - аспирант отдела клинической электрофизиологии и рентгенохирургических методов лечения нарушений ритма сердца Научно-исследовательского института клинической кардиологии им. А.Л. Мясникова'; ORCID: https://orcid.org/0000-0002-3550-6111.

E-mail: azhambeev@yandex.ru
Салами Хуссейн Фаез - врач сердечно-сосудистый хирург 7-го «а» клинического отделения Научноисследовательского института клинической кардиологии им. А.Л. Мясникова'; ORCID: https://orcid.org/0000-0001-9751-7767. E-mail: hussein_salami@mail.ru

Гусева Елена Владимировна - аспирант отдела клинической электрофизиологии и рентгенохирургических методов лечения нарушений ритма сердца Научно-исследовательского института клинической кардиологии им. А.Л. Мясникова'; ORCID: https://orcid.org/0000-0001-6500-3649.

E-mail: gev1994@list.ru

Тарасовский Геннадий Сергеевич - врачкардиолог 7-го «а» клинического отделения Научно-исследовательского института клинической кардиологии им. А.Л. Мясникова'; ORCID: https://orcid. org/0000-0002-2143-8912. E-mail: gena80@yandex.ru

Шарф Татьяна Владимировна - науч. сотр. Научноисследовательского института экспериментальной кардиологии'; ORCID: https://orcid.org/0000-0003-19939264. E-mail: tsharf@rambler.ru

Стукалова Ольга Владимировна - канд. мед. наук, ст. науч. сотр. отдела томографии Научноисследовательского института клинической кардиологии им. А.Л. Мясникова'; ORCID: https://orcid. org/0000-0001-8377-2388. E-mail: olgastukalova@mail.ru
Гупало Елена Михайловна - канд. мед. наук, науч. сотр. отдела клинической электрофизиологии и рентгенохирургических методов лечения нарушений ритма сердца Научно-исследовательского института клинической кардиологии им. А.Л. Мясникова'; ORCID: https://orcid.org/0000-0002-0063-5474.

E-mail: eleno4ka_g@mail.ru

Миронова Наталия Александровна - канд. мед. наук, ст. науч. сотр. отдела клинической электрофизиологии и рентгенохирургических методов лечения нарушений ритма сердца Научно-исследовательского института клинической кардиологии им. А.Л. Мясникова'; ORCID: https://orcid.org/0000-0002-0063-5474.

E-mail:mirona01@mail.ru

Скворцов Андрей Александрович - д-р мед. наук, вед. науч. сотр. отдела заболеваний миокарда и сердечной недостаточности Научноисследовательского института клинической кардиологии им. А.Л. Мясникова'; ORCID: https://orcid. org/0000-0003-2712-927X. E-mail: skvortsov00@yandex.ru

Голицын Сергей Павлович - д-р мед. наук, профессор, руководитель отдела клинической электрофизиологии и рентгенохирургических методов лечения нарушений ритма сердца Научноисследовательского института клинической кардиологии им. А.Л. Мясникова'; ORCID: https://orcid. org/0000-0001-9913-9974. E-mail: golitsyn@mail.ru

1 ФГБУ «Национальный медицинский исследовательский центр кардиологии» Минздрава России; 121552, г. Москва, ул. 3-я Черепковская, 15а, Российская Федерация 
считалась дата имплантации устройств, выбранных для лечения ХСН: СРТ или МСС. Через 6, 1012 и 18-24 месяца после имплантации устройств у всех больных оценивали общее состояние, врачом-кардиологом проводились клинический осмотр и опрос, тест 6-минутной ходьбы, выполняли определение класса ХCH, оценку наличия и выраженности застойных явлений в легких, определение уровня биомаркеров крови (NT-proBNP и sST2), запись электрокардиограммы (ЭКГ) в 12 отведениях, трансторакальную ЭхоКГ, а также проверку параметров работы имплантированных устройств. Критериями положительных результатов применения устройств СРТ и МСС были уменьшение конечно-систолического объема левого желудочка (ЛЖ) по ЭхоКГ на 15\% и более через 6 месяцев наблюдения $[7,16]$ по сравнению с его исходным значением, а также отсутствие декомпенсаций $\mathrm{XCH}$ в течение данного периода времени.

При обнаружении любых клинических проявлений декомпенсации ХСН выполняли внеочередной осмотр больных с оценкой их клинического статуса и детализацией работы имплантированных устройств по данным их интеррогирования, трансторакальную ЭхоКГ, рентгенографию органов грудной клетки, а при необходимости - внеочередное определение уровня биомаркеров (NTproBNP и sST2).

По результатам осмотра в каждом конкретном случае решался вопрос о целесообразности госпитализации для коррекции лекарственной терапии. По результатам наблюдения оценивали точки исследования: промежуточные (наличие признаков ответа на применение устройств СРТ или МСС, возникновение декомпенсации ХСН и жизнеугрожающих желудочковых тахиаритмий) и конечные (смерть пациента от сердечных причин (внезапная смерть, декомпенсация ХСН), окончание наблюдения в течение 24 месяцев).

\section{Критерии соответствия}

Критериями включения пациентов в исследование служили наличие структурного поражения миокарда ишемической либо неишемической этиологии со значительным снижением сократительной функции сердца (значения фракции выброса (ФВ) ЛЖ менее 35\% по данным трансторакальной ЭхоКГ) и клиническими признаками XCH II-III функционального класса (ФК) по NYHA (New York Heart Association - НьюЙоркская кардиологическая ассоциация).

В исследование не включались пациенты, у которых ХCH была следствием врожденных либо приобретенных пороков сердца, больные с декомпенсированной ХCH (IV ФК по NYHA), неконтролируемой артериальной гипертензией, высокой легочной гипертензией (значения систолического давления в легочной артерии более 100 мм рт. ст.), острой соматической патологией (острый инфаркт миокарда, острый миокардит, острые инфекционные заболевания и др.), пациенты, нуждающиеся в реваскуляризации миокарда в связи с наличием стенокардии напряжения IIIIV ФК или стенокардии покоя, с тяжелой сопутствующей патологией, в том числе тяжелой печеночной и почечной недостаточностью (снижение скорости клубочковой фильтрации менее 30 мл/мин), гипертиреозом, а также с онкологическими заболеваниями и другими состояниями, которые могли бы помешать участию пациента в исследовании.

Из исследования исключались пациенты, имеющие противопоказания к проведению МРТ сердца с контрастированием (наличие ранее имплантированных устройств, кроме совместимых с МРТ приборов, наличие механических клапанов сердца, клаустрофобии, аллергии на йод или контрастные препараты и др.), а также больные, имеющие противопоказания к имплантации устройств СРТ с функцией дефибриллятора (СРТ-Д) или МСС.

\section{Условия проведения}

Исследование проводилось в ФГБУ «НМИЦ кардиологии» Минздрава России.

\section{Описание медицинского вмешательства}

Обследование пациентов включало определение значений биомаркеров крови NT-proBNP и sST2, проведение стандартной 12-канальной ЭКГ, трансторакальной ЭхоКГ и МРТ сердца с контрастированием наряду с использованием других методов стандартного клинико-инструментального и лабораторного обследования.

Определение значений указанных биомаркеров выполняли в отделе нейрогуморальных и иммунологических исследований НИИ клинической кардиологии им. А.Л. Мясникова ФГБУ «НМИЦ кардиологии» Минздрава России, для чего у всех включенных в исследование пациентов проводили забор крови из локтевой вены с последующим центрифугированием. Концентрации NT-proBNP определяли в сыворотке крови на электрохемилюминесцентном анализаторе Cobas e 411 Roche/Hitachi (Япония) с помощью набоpa proBNP II Cobas (Roche Diagnostics $\mathrm{GmbH}$, Германия). Диапазон измерений NT-proBNP coставил 5-35000 пг/мл. Концентрации sST2-peцептора определяли в плазме крови. После 
центрифугирования в течение 15 минут со скоростью 2500 об/мин при температуре $4{ }^{\circ} \mathrm{C}$ пробы плазмы хранились при температуре $-70{ }^{\circ} \mathrm{C}$ в микропробирках типа Eppendorf в объеме 500 мкл. Анализ выполняли на приборе Luminometer Photometer LMA 01 фирмы Beckman Coulter (450 нм) с помощью набора для количественного определения sST2 методом иммуноферментного анализа (Critical Diagnostics Presage ${ }^{\circledR}$ ST2 Assay) в соответствии с прилагаемой инструкцией. Чувствительность метода составила 1,8 нг/мл.

Трансторакальную ЭхоКГ проводили с использованием М- и В-режимов при синхронной записи ЭКГ по стандартной методике, принятой в НИИ клинической кардиологии им. А.Л. Мясникова. При использовании парастернального и верхушечного доступов исследовали размеры и объемы полостей сердца, систолическое давление в легочной артерии, толщину стенок ЛЖ, общую ФВ ЛЖ по методу Симпсона, а также наличие клапанных регургитаций.

Исследования МРТ сердца выполняли на сверхпроводящем томографе мощностью 1,5 Тесла (Siemens AG, Германия) с поверхностной радиочастотной катушкой для грудной клетки и синхронизацией с ЭКГ. Исследования проводили по стандартной методике, принятой в НИИ клинической кардиологии им. А.Л. Мясникова [12]. Контрастный препарат гадоверсетамид на основе гадолиния вводили внутривенно в дозе 0,15 ммоль (0,3 мл) на 1 кг массы тела пациента. Сканирование выполняли через 10-15 минут после инъекции. Помимо оценки морфологии и функции сердца проводили анализ распределения контрастного препарата в миокарде, выявляли участки его патологического накопления. Анализ изображений МРТ выполняли с использованием платформы сертифицированной программы CVI42 (Circle Cardiovascular Imaging Inc., Канада), оценивающей наличие, локализацию и выраженность накопления контрастного вещества в миокарде ЛЖ. По итогам анализа программа автоматически вычисляла количества (в граммах) и доли (в процентах) фиброза и частично жизнеспособного миокарда или так называемой серой зоны в ЛЖ.

\section{Анализ в группах}

Критериям включения и невключения в исследование соответствовал 51 пациент (40 мужчин и 11 женщин), средний возраст которых составил 56 лет (от 26 до 79 лет). По результатам обследования у 22 (43\%) пациентов был диагностирован постинфарктный кардиосклероз, а у остальных
29 (57\%) установлено наличие неишемической кардиомиопатии. Из них у 19 (37\%) пациентов была диагностирована дилатационная кардиомиопатия, у 9 (18\%) - декомпенсированное «гипертоническое сердце», у 1 (2\%) - постмиокардитический кардиосклероз. Пациенты имели значения ФВ ЛЖ в диапазоне от 18 до 34\% по данным ЭхоКГ, медиана ФВ ЛЖ составила 25\% [23; 33]. У 24 больных был установлен II ФК ХСН, у 27 - III ФК по NYHA. Bсе пациенты, включенные в исследование, получали оптимальную медикаментозную терапию в соответствии с имеющимся заболеванием согласно клиническим рекомендациям [16]. Препараты различных лекарственных классов были распределены между больными следующим образом: ингибиторы ангиотензинпревращающего фермента или антагонисты рецепторов ангиотензина II принимали 45 (88\%) пациентов, бета-адреноблокаторы - 50 (98\%), антагонисты минералокортикоидных рецепторов - 48 (94\%), петлевые диуретики - 47 (92\%), дигоксин $21(41 \%)$.

Всем включенным в исследование пациентам в условиях продолжающейся медикаментозной терапии в соответствии с индивидуальными показаниями были имплантированы приборы для немедикаментозного лечения ХCH: СРТ-Д 39 пациентам, устройства для проведения MCC - 12 больным. Пяти пациентам с MCC дополнительно были имплантированы кардиовертеры-дефибрилляторы по показаниям первичной или вторичной профилактики внезапной сердечной смерти.

\section{Этическая экспертиза}

Исследование выполнено в соответствии со стандартами надлежащей клинической практики и принципами Хельсинкской декларации Всемирной медицинской ассоциации. Протокол исследования одобрен независимым Комитетом по вопросам этики в клинической кардиологии НИИ клинической кардиологии им. А.Л. Мясникова ФГБУ «НМИЦ кардиологии» Минздрава России (протокол № 230 заседания комитета от 30.10.2017). Исследование выполнялось на базе этого же учреждения, где проводили обследование, лечение и дальнейшее наблюдение включенных в него пациентов. До включения в исследование у всех его участников было получено письменное информированное согласие.

\section{Статистический анализ}

Статистическую обработку данных проводили с использованием пакетов программ Statistica 7.0 
(StatSoft), SPSS 22.0 (Norman Nie, Hadlai Hull \& Dale Bent, IBM), MedCalc 5.0 (MedCalc Software Ltd). Изучаемые параметры были обозначены в качестве медианы и интерквартильного размаха (25-го и 75-го перцентилей). Количество случаев в группах обозначали как $n$. Для сравнительного анализа признаков использовали непараметрические методы: U-тест Манна - Уитни для сравнения непрерывных величин и точный двусторонний тест Фишера для сравнения дискретных величин. Для выявления независимых предикторов возникновения аритмических событий применяли логистический вариант многофакторного регрессионного анализа признаков, для определения «отрезных» значений признаков, продемонстрировавших статистически значимые $(\mathrm{p}<0,05)$ различия между группами, - ROC-анализ с помощью построения характеристических кривых зависимости чувствительности и специфичности исследуемых признаков.

\section{Результаты}

\section{Объекты (участники) исследования}

Характеристика групп больных с разными типами имплантированных устройств на момент начала проспективного наблюдения дана в табл. 1. Как видно из ее данных, пациентов группы СРТ отличали более высокие значения длительности комплексов QRS, а также частоты выявления блокады левой ножки пучка Гиса, что определяет показания к применению этого метода лечения. Кроме того, пациенты группы СРТ были значимо старше, чем больные с МСС: 61 [56; 69] и 45 [37; 56] лет соответственно, и имели более высокие исходные значения NT-proBNP - 2343 [1075; 3468] и 1110 [687; 2210] пг/мл соответственно $(\mathrm{p}<0,05)$. При этом значимых различий между указанными группами больных по характеру лекарственной терапии ХCH, размерам левых отделов сердца, значениям ФВ ЛЖ по данным ЭхоКГ, а также параметрам фиброзно-рубцового поражения миокарда по данным МРТ сердца с контрастированием выявлено не было.

Через 6 месяцев после включения в исследование уменьшение конечно-систолического объема ЛЖ по данным ЭхоКГ на 15\% и более, принятое в качестве критерия положительного результата проводимого немедикаментозного печения, отмечено у 21 (54\%) из 39 больных группы СРТ и 7 (58\%) из 12 пациентов группы МСС. Принимая во внимание имеющиеся различия между группами пациентов с имплантированными устройствами СРТ и МСС по ряду клинико-инструментальных и лабораторных показателей (см. табл. 1), а также различные механизмы лечебного воздействия на больных $\mathrm{XCH}$, оказываемого данными приборами, анализ факторов, предрасполагающих к достижению положительных результатов применения каждого из типов устройств, проводился раздельно.

\section{Основные результаты исследования}

Анализ клинико-инструментальных и лабораторных параметров, ассоциированных с положительными результатами применения сердечной ресинхронизирующей терапии у больных хронической сердечной недостаточностью

Двадцать один больной с достигнутым эффектом от проведения СРТ по критериям ЭхоКГ сформировал группу «СРТ+», оставшиеся 18 пациентов вошли в группу «СРТ-».

Как показал однофакторный анализ (табл. 2), больные ХCH с наличием положительных результатов (группа «СРТ+», $\mathrm{n}=21$ ) применения устройств СРТ статистически значимо отличались от пациентов с отсутствием таковых (группа «СРТ-», n=18) меньшей долей больных c III ФК ХСН по NYHA: 39 и 72\% соответственно $(\mathrm{p}=0,045)$. В группе «СРТ+» в 3 раза реже встречались пациенты с постоянной формой фибрилляции предсердий (14 и 44\% соответственно, $\mathrm{p}=0,041)$, и, как следствие, более редкой была потребность в постоянном приеме дигоксина (29 и $67 \%$ соответственно, $\mathrm{p}=0,025)$.

В то же время пациенты группы «СРТ-» имели более высокие концентрации NT-proBNP - 3607 $[1367 ; 5171]$ пг/мл и sST2 - $50[23 ; 69]$ нг/мл в плазме крови, большие размеры полости левого предсердия - 5,2 $[4,9 ; 5,4]$ см и правого желудочка - 3,5 [2,7; 3,7] см по данным ЭхоКГ, а также большее количество сегментов стенки ЛЖ с фиброзом по данным МРТ сердца - $5[3 ; 8]$ (все значения $\mathrm{p}<0,05$, см. табл. 2).

Анализ клинико-инструментальных и лабораторных параметров, ассоциированных с положительными результатами применения модуляции сердечной сократимости

Эффективность проведения МСС была подтверждена эхокардиографическими критериями у 7 больных, сформировавших группу «МСС+». Пять других больных вошли в группу «МСС-». Результаты сопоставления этих групп с помощью методов однофакторного и многофакторного анализа представлены в табл. 3. Пациенты группы «МСС+» отличались от группы «МСС-» более молодым возрастом: 39 [33; 51] и 57 [39; 65] лет соответственно $(p=0,045)$, меньшей массой 
Таблица 1. Характеристика пациентов исследуемых групп

\begin{tabular}{|c|c|c|}
\hline \multirow[t]{2}{*}{ Параметр } & \multicolumn{2}{|l|}{ Группа } \\
\hline & CPT $(n=39)$ & $\operatorname{MCC}(n=12)$ \\
\hline \multicolumn{3}{|l|}{ Клинические параметры } \\
\hline Возраст, годы ${ }^{*}$ & $61[56 ; 69]$ & $45[37 ; 56]^{* *}$ \\
\hline Пол (мужской / женский) & $29 / 10$ & $10 / 2$ \\
\hline Наличие ПИКС, n (\%) & $21(54)$ & $3(25)$ \\
\hline Признаки XCH II/III ФК, n (\%) & $17(43) / 22(57)$ & $6(50) / 6(50)$ \\
\hline Наличие ФП в анамнезе, n (\%) & $16(40)$ & $3(25)$ \\
\hline \multicolumn{3}{|l|}{ Лекарственная терапия } \\
\hline иАПФ или АРА/АРНИ, n (\%) & $34(87)$ & $11(92)$ \\
\hline Бета-адреноблокаторы, n (\%) & $39(100)$ & $11(92)$ \\
\hline AMKP, n (\%) & $36(92)$ & $12(100)$ \\
\hline Петлевые диуретики, n (\%) & $38(97)$ & $9(75)$ \\
\hline Дигоксин, $\mathrm{n}(\%)$ & $16(40)$ & $5(42)$ \\
\hline \multicolumn{3}{|l|}{ Значения биомаркеров крови (исходно)* } \\
\hline NT-proBNP, пг/мл & $2343[1075 ; 3468]$ & $1110[687 ; 2210]^{* *}$ \\
\hline sST2, нг/мл & $26[21 ; 50]$ & $21[20 ; 37]$ \\
\hline \multicolumn{3}{|l|}{ Данные ЭКГ (исходно) } \\
\hline Длительность QRS, мc ${ }^{*}$ & $180[159 ; 192]$ & $113[106 ; 125]^{* *}$ \\
\hline Наличие БЛНПГ, n (\%) & $34(87)$ & $2(17)^{* * *}$ \\
\hline \multicolumn{3}{|l|}{ Данные ЭхоКГ (исходно)* } \\
\hline ПЗР лП, см & $4,9[4,6 ; 5,2]$ & $5,0[4,4 ; 5,2]$ \\
\hline КСР ЛЖ, см & $6,2[5,7 ; 6,8]$ & $6,5[5,8 ; 7,3]$ \\
\hline КДР ЛЖ, см & $7,3[6,9 ; 7,8]$ & $7,2[7,0 ; 8,3]$ \\
\hline СДЛА, мм рт. ст. & $41[35 ; 57]$ & $30[23 ; 33]^{* *}$ \\
\hline ФВ ЛЖ, \% & $25[24 ; 33]$ & $26[23 ; 30]$ \\
\hline \multicolumn{3}{|c|}{ Данные МРТ сердца с контрастированием (исходно)* } \\
\hline Масса миокарда, г & $122[97 ; 159]$ & $100[97 ; 130]$ \\
\hline Масса фиброза, г & $10,2[5,1 ; 16,6]$ & $6,5[4,2 ; 8,2]$ \\
\hline Масса «серой зоны», г & $25,0[20,8 ; 31,4]$ & $25,3[15,9 ; 29,1]$ \\
\hline Количество сегментов ЛЖ с фиброзом & $3[1 ; 6]$ & $1[0 ; 3]$ \\
\hline
\end{tabular}

АМКР - антагонисты минералокортикоидных рецепторов, АРА - антагонист рецепторов ангиотензина II, АРНИ - ингибитор ангиотензиновых рецепторов и неприлизина, БЛНПГ - блокада левой ножки пучка Гиса, иАПФ - ингибиторы ангиотензинпревращающего фермента, КДР - конечно-диастолический размер, КСР - конечно-систолический размер, ЛЖ - левый желудочек, ЛП - левое предсердие, МРТ - магнитно-резонансная томография, МСС - модулятор сердечной сократимости, ПЗР - передне-задний размер, ПИКС - постинфарктный кардиосклероз, СДЛА - систолическое давление в легочной артерии, СРТ - сердечная ресинхронизирующая терапия, ФВ - фракция выброса, ФК функциональный класс, ФП - фибрилляция предсердий, ХСН - хроническая сердечная недостаточность, ЭКГ - электрокардиография, ЭхоКГ - эхокардиография

"Данные представлены в виде медианы и интерквартильного размаха (Ме [25\%; 75\%])

" $\mathrm{p}<0,05$ при сравнении групп СРТ и МСС

тела: 80 [69; 85] и 95 [89; 95] кг соответственно $(\mathrm{p}=0,047)$ и, как следствие, меньшим индексом массы тела (ИМТ): 25 [22; 27] и 32 [29; 33] кг/м² соответственно $(p=0,041)$. При этом пациенты группы «МСС-» имели более высокие концентрации биомаркеров в плазме крови: NT-proBNP 2340 [1110; 2930] пг/мл и sST2 - 41 [26; 49] нг/мл, большую длительность интервала QRS по ЭКГ $125[114 ; 135]$ мс, большие размеры левого предсердия - 5,2 [5,0; 5,4] см и большие размеры ЛЖ по данным ЭхоКГ: больший конечно-систолический размер ЛЖ - 7,5 [7,2; 7,6] см, а также больший конечно-диастолический размер ЛЖ - 8,4 $[8,2 ; 8,5]$ см (все значения $\mathrm{p}<0,05$, см. табл. 3). Обращало на себя внимание, что больные с наличием эффекта от применения СРТ и МСС и без такового не отличались друг от друга по исходным значениям ФВ ЛЖ по данным ЭхоКГ (см. табл. 2 и 3).

Определение независимых признаков положительных результатов применения сердечной ресинхронизирующей терапии и модуляиии сердечной 
Таблица 2. Результаты однофакторного и многофакторного сравнительного анализа клинико-инструментальных и лабораторных показателей в группах больных хронической сердечной недостаточностью в зависимости от наличия (СРТ+) или отсутствия (СРТ-) эффекта от применения сердечной ресинхронизирующей терапии

\begin{tabular}{|c|c|c|c|c|}
\hline \multirow[t]{2}{*}{ Параметр } & \multicolumn{2}{|l|}{ Группа } & \multicolumn{2}{|l|}{ Значение $p$} \\
\hline & $C P T+(n=21)$ & CPT- $(n=18)$ & однофакторный анализ & многофакторный анализ \\
\hline \multicolumn{5}{|l|}{ Клинические показатели } \\
\hline Признаки XCH II/III ФК, n (\%) & $13(61) / 8(39)$ & $5(28) / 13(72)$ & $0,045^{* *}$ & $>0,05$ \\
\hline Наличие постоянной ФП, n (\%) & $3(14)$ & $8(44)$ & $0,041^{* *}$ & $>0,05$ \\
\hline Терапия дигоксином, n (\%) & $6(29)$ & $12(67)$ & $0,025^{* *}$ & $>0,05$ \\
\hline \multicolumn{5}{|l|}{ Значения биомаркеров крови* } \\
\hline NT-proBNP, пг/мл & $1554[762 ; 2343]^{* *}$ & $3607[1367 ; 5171]^{* *}$ & $0,028^{* *}$ & $0,005^{* *}$ \\
\hline sST2, нг/мл & $24[19 ; 45]^{* *}$ & $50[23 ; 69]^{* *}$ & $0,019^{* *}$ & $0,005^{* *}$ \\
\hline \multicolumn{5}{|l|}{ Параметры ЭхоКГ* } \\
\hline ПЗР ЛП, см & $4,7[4,5 ; 5,2]^{* *}$ & $5,2[4,9 ; 5,4]^{* *}$ & $0,022^{* *}$ & $0,002^{* *}$ \\
\hline ПЗР ПЖ, см & $2,8[2,4 ; 3,1]$ & $3,5[2,7 ; 3,7]$ & $0,009^{* *}$ & $>0,05$ \\
\hline КДР ЛЖ, см & $7,3[6,8 ; 7,9]$ & $7,3[6,8 ; 7,6]$ & $>0,05$ & $>0,05$ \\
\hline КСР ЛЖ, см & $6,2[5,7 ; 6,8]$ & $6,2[5,9 ; 6,8]$ & $>0,05$ & $>0,05$ \\
\hline ФВ ЛЖ, \% & $27[25 ; 30]$ & $28[23 ; 33]$ & $>0,05$ & $>0,05$ \\
\hline \multicolumn{5}{|l|}{ Параметры МРТ сердца* } \\
\hline Масса фиброза, г & $4,2[3,7 ; 6,7]$ & $11,6[8,1 ; 21,5]$ & $0,003^{* *}$ & $>0,05$ \\
\hline Количество сегментов фиброза в ЛЖ & $1[0 ; 1]^{* *}$ & $5[3 ; 8]^{* *}$ & $0,019^{* *}$ & $0,001^{* *}$ \\
\hline \multicolumn{5}{|l|}{ Результаты наблюдения (18-24 месяца) } \\
\hline ФВ ЛЖ, \% (по ЭхоКГ)* & $39[30 ; 44]$ & $25[20 ; 30]$ & $0,002^{* *}$ & \\
\hline Наличие декомпенсации XCH, n (\%) & $4(19)$ & $12(67)$ & $0,003^{* *}$ & \\
\hline Умершие, n (\%) & $1(5)$ & $4(22)$ & 0,16 & \\
\hline
\end{tabular}

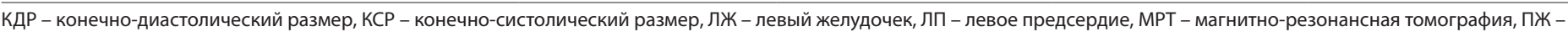

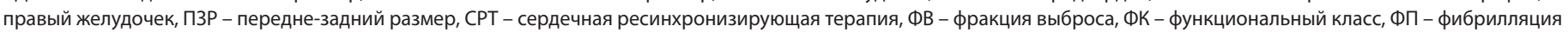
предсердий, ХCH - хроническая сердечная недостаточность, ЭхоКГ - эхокардиография

"Данные представлены в виде медианы и интерквартильного размаха (Ме [25\%; 75\%])

** Показатели, отобранные по итогам многофакторного регрессионного анализа в качестве независимых признаков ответа больных ХСН на применение устройств СРТ

сократимости у больных хронической сердечной недостаточностью по результатам многофакторного анализа

Для выявления независимых факторов достижения эффекта от применения СРТ и МСС у включенных в исследование пациентов все показатели, продемонстрировавшие статистически значимые различия между группами с наличием и отсутствием положительного результата от применения данных устройств, были включены в процедуру многофакторного регрессионного анализа. По результатам этого анализа независимыми признаками, сопряженными с достижением эхокардиографического критерия эффективности СРТ, стали четыре показателя: 1) более высокое значение концентраций sST2 в плазме крови, 2) более высокое значение концентрации NT-proBNP в плазме крови, 3) наличие в миокарде ЛЖ признаков фиброза по данным МРТ сердца с контрастированием, а также 4) больший передне-задний размер левого предсердия по данным ЭхоКГ (см. табл. 2).

Поиск предикторов эффективности МСС также обнаружил четыре показателя: 1) больший возраст больных, 2) больший ИМТ, 3) более высокую концентрацию биомаркера крови SST2, а также 4) больший конечно-диастолический размер ЛЖ по данным ЭхоКГ (см. табл. 3).

Определение «отрезньх» значений независимых признаков, ассоциированных с положительными результатами применения СРТ и МСС (резульmamı ROC-анализа)

Для определения «отрезных» значений признаков, ассоциированных с эффективностью применения СРТ и МСС, проведена процедура ROC-анализа показателей, отобранных ранее методом многофакторного регрессионного анализа (табл. 4). 
Таблица 3. Результаты однофакторного и многофакторного анализа клинико-инструментальных и лабораторных показателей в группах больных хронической сердечной недостаточностью в зависимости от наличия (МСС+) или отсутствия (МСС-) ответа на применение имплантированных устройств модуляции сердечной сократимости

\begin{tabular}{|c|c|c|c|c|}
\hline \multirow[t]{2}{*}{ Параметр } & \multicolumn{2}{|l|}{ Группа } & \multicolumn{2}{|l|}{ Значение $p$} \\
\hline & $\operatorname{MCC}+(n=7)$ & MCC- $(n=5)$ & однофакторный анализ & многофакторный анализ \\
\hline \multicolumn{5}{|l|}{ Клинические показатели“ } \\
\hline Возраст, годы & $39[33 ; 51]^{* * *}$ & $57[39 ; 65]^{* *}$ & $0,045^{* *}$ & $0,05^{* *}$ \\
\hline Масса тела, кг & $80[69 ; 85]$ & $95[89 ; 95]$ & $0,047^{* *}$ & $>0,05$ \\
\hline Индекс массы тела, кг/м² & $25[22 ; 27]^{* * *}$ & $32[29 ; 33]^{* *}$ & $0,041^{* *}$ & $0,05^{* *}$ \\
\hline \multicolumn{5}{|l|}{ Значения биомаркеров крови" } \\
\hline NT-proBNP, пг/мл & $791[596 ; 1054]$ & $2340[1110 ; 2930]$ & $0,031^{* *}$ & $>0,05$ \\
\hline sST2, нг/мл & $20[19 ; 21]^{* *}$ & $41[26 ; 49]^{* *}$ & $0,042^{* *}$ & $0,042^{* *}$ \\
\hline \multicolumn{5}{|l|}{ Параметры ЭКГ“ } \\
\hline Длительность QRS, MC & $110[95 ; 125]$ & $125[114 ; 135]$ & $0,048^{* *}$ & $>0,05$ \\
\hline \multicolumn{5}{|l|}{ Параметры ЭхоКГ“ } \\
\hline ПЗР лП, см & $4,5[4,0 ; 4,7]$ & $5,2[5,0 ; 5,4]$ & $0,01^{* *}$ & $>0,05$ \\
\hline КДР ЛЖ, см & $7,1[6,9 ; 7,2]^{* *}$ & $8,4[8,2 ; 8,5]^{* *}$ & $0,048^{* * *}$ & $0,002^{* * *}$ \\
\hline КСР ЛЖ, см & $6,1[5,8 ; 6,5]$ & $7,5[7,2 ; 7,6]$ & $0,048^{* * *}$ & $0,002^{* *}$ \\
\hline Фв лж, \% & $28[26 ; 32]$ & $24[23 ; 27]$ & $>0,05$ & $>0,05$ \\
\hline \multicolumn{5}{|c|}{ Результаты наблюдения (18-24 месяца)* } \\
\hline ФВ лЖ, \% (по ЭхоКГ) & $45[37 ; 47]$ & $26[23 ; 29]$ & $0,006^{* *}$ & \\
\hline $\begin{array}{l}\text { Наличие декомпенсации XСН, } \\
\text { n (\%) }\end{array}$ & $1(14)$ & $5(100)$ & $0,015^{* *}$ & \\
\hline Умершие, n (\%) & 0 & $2(40)$ & 0,155 & \\
\hline
\end{tabular}

КДР - конечно-диастолический размер, КСР - конечно-систолический размер, Лж - левый желудочек, ЛП - левое предсердие, МРТ - магнитно-резонансная томография,

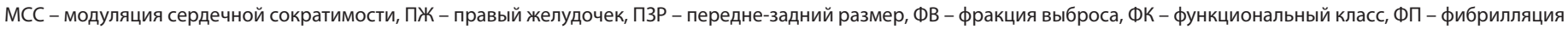
предсердий, ХСН - хроническая сердечная недостаточность, ЭКГ - электрокардиография, ЭхоКГ - эхокардиография

* Данные представлены в виде медианы и интерквартильного размаха (Ме [25\%; 75\%])

"* Показатели, отобранные по итогам многофакторного регрессионного анализа в качестве независимых признаков ответа больных ХСН на применение устройств МСС

Для четырех показателей, выделенных в качестве предикторов достижения эффекта от проведения CPT методом ROC-анализа, были определены следующие «отрезные» значения:

1) наличие менее 3 сегментов фиброза в ЛЖ по данным МРТ сердца;

2) значение концентрации NT-proBNP в плазме крови исходно менее 3900 пг/мл;

3) передне-задний размер левого предсердия менее 4,8 см по данным ЭхоКГ;

4) значение концентрации SST2 в плазме крови исходно менее 50 нг/мл.

Наличие 2 из 4 представленных выше признаков позволяло прогнозировать положительный результат применения СРТ с точностью $87 \%$ (чувствительность 90\%, специфичность 83\%).

По результатам ROC-анализа «отрезными» значениями для выделенных независимых предикторов достижения эхокардиографических критериев эффекта от применения МСС у обследованных пациентов были:

1) значение ИМТ менее $28 \mathrm{\kappa r} / \mathrm{m}^{2}$;

2) значение конечно-диастолического размера ЛЖ менее 7,8 см по данным ЭхоКГ;

3) исходное значение концентрации биомаркеpa sST2 в плазме крови менее 29 нг/мл;

4) возраст больных менее 56 лет.

При наличии 2 из 4 вышеуказанных признаков было возможно прогнозировать положительный результат применения МСС с точностью 92\% (чувствительность 86\%, специфичность 100\%).

\section{Дополнительные результаты исследования}

Результаты наблюдения пациентов

За время наблюдения, составившего 24 (19-28) месяца, явления декомпенсации ХСН статистически значимо чаще регистрировали у больных, не имевших эхокардиографических критериев 
Таблица 4. Результаты определения «отрезных» значений для независимых признаков, ассоциированных с достижением критериев эффективности применения сердечной ресинхронизирующей терапии и модуляции сердечной сократимости у исследованных больных (по данным ROC-анализа)

\begin{tabular}{|c|c|c|c|c|}
\hline № $п / п$ & Клинический параметр & $\begin{array}{l}\text { Площадь под ROC-кривой } \\
\text { (95\% ДИ) }\end{array}$ & Чувствительность, \% & Специфичность, \% \\
\hline \multicolumn{5}{|c|}{ ROC-анализ признаков эффективности применения СРT } \\
\hline 1 & $\begin{array}{c}\text { Наличие менее } 3 \text { сегментов эндомиокардиального } \\
\text { фиброза в ЛЖ по данным МРТ сердца }\end{array}$ & $0,91(0,75-1,00)$ & 100 & 90 \\
\hline 2 & Значение NT-proBNP исходно менее 3900 пг/мл & $0,71(0,55-0,89)$ & 50 & 90 \\
\hline 3 & ПЗР ЛП менее 4,8 см (по данным ЭхоКГ) & $0,71(0,55-0,89)$ & 63 & 58 \\
\hline 4 & Значение sST2 исходно менее 50 нг/мл & $0,70(0,54-0,87)$ & 56 & 90 \\
\hline \multicolumn{5}{|c|}{ ROC-анализ признаков эффективности применения МСC } \\
\hline 1 & Значение ИМТ менее 28 кг/м² & $0,90(0,69-1,00)$ & 100 & 86 \\
\hline 2 & КДР ЛЖ менее 7,8 см (по данным ЭхоКГ) & $0,85(0,59-1,00)$ & 100 & 80 \\
\hline 3 & Значение sST2 исходно менее 29 нг/мл & $0,80(0,52-1,00)$ & 80 & 86 \\
\hline 4 & Возраст больных менее 56 лет & $0,76(0,45-1,00)$ & 100 & 60 \\
\hline
\end{tabular}

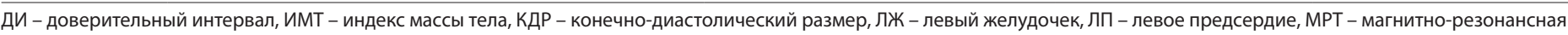
томография, МСС - модуляция сердечной сократимости, ПЗР - передне-задний размер, СРТ - сердечная ресинхронизирующая терапия, ЭхоКГ - эхокардиография

эффекта применения СРТ и МСС - в 67 и 100\% случаев соответственно по сравнению с пациентами с наличием такого эффекта (у 19 и 14\% больных соответственно, $\mathrm{p}<0,05)$. За этот же период времени от сердечных причин умерли 7 (14\%) пациентов, из них 2 - внезапно, 5 - вследствие острой декомпенсации ХСН. При этом в 6 (86\%) из 7 случаев сердечная смерть отмечена у пациентов, не продемонстрировавших по данным ЭхоКГ положительного эффекта в ответ на применение СРТ или МCC.

\section{Нежелательные явления}

При проведении исследования нежелательные явления отсутствовали.

\section{Обсуждение}

Ограниченная эффективность немедикаментозной терапии больных ХCH и непредсказуемость результатов такого лечения в значительной части случаев могут быть следствием несовершенства используемых до настоящего времени критериев отбора пациентов для такого рода вмешательств. Применительно к СРT, по мнению G.B. Bleeker и соавт. [17], наличие или отсутствие эффекта от применения ресинхронизирующих устройств может определяться взаимодействием большого количества факторов. Среди них в разное время рассматривались выраженность фиброзно-рубцового повреждения нижнебоковой стенки ЛЖ $[5,17]$, размеры левых камер сердца [18], особенности электрической $[12,19]$ и механической диссинхронии желудочков [12] и многие другие. В нашей работе подтверждена роль ряда ранее известных факторов, предрасполагающих к достижению желаемого результата применения СРТ и МСС у больных ХСН. Наряду с этим выявлены новые предикторы успеха использования данных методов, их мы обсудим детальнее.

\section{Индекс массы тела}

Одной из находок данной работы стало выявление взаимосвязи между ИМТ более 27 кг/м² и отсутствием эффекта от применения МСС у больных ХСН. Эти результаты в какой-то степени созвучны итогам работы J.C. Hsu и соавт. [7], которая, однако, была посвящена изучению эффекта СРТ. Авторы показали, что значения ИМТ менее 30 кг/м² были ассоциированы с достижением значимых положительных результатов от проведения СРТ у больных ХСН. Известно, что избыток жира в организме ассоциируется с системным воспалением [20], увеличением преднагрузки и постнагрузки на сердце [21], а также с возникновением сахарного диабета, артериальной гипертензии и синдрома ночного апноэ - явлений, каждое из которых может утяжелять течение ХCH [22]. Вместе с тем наши данные противоречат ранее описанному феномену, известному в литературе как парадокс ожирения, согласно которому избыточная масса тела и ожирение ассоциированы с меньшим риском сердечно-сосудистых событий у пациентов с ХСН [23]. Поскольку ИМТ - сложная переменная, дериват роста и веса, оценка связи ИМТ с ответом на применение устройств МСС может оказаться трудной. ИМТ больных ХСН зависит не только от индивидуальных конституциональных особенностей пациентов, включая проценты жировой и мышечной тканей, но и от степени 
перегрузки организма избыточной жидкостью. Несмотря на то что имплантация устройств МСС и СРТ обычно выполняется после предварительной компенсации явлений ХСН, одним из факторов, предрасполагавших к отсутствию ответа на применение МСС, может быть более выраженная тяжесть ХСН, при которой полная медикаментозная компенсация пациентов не всегда достижима.

\section{Размеры левого предсердия}

Еще одним маркером, ассоциированным с эффективностью устройств СРТ у больных ХCH, согласно результатам нашего исследования, было значение передне-заднего размера левого предсердия менее 4,8 см по данным ЭхоКГ. L. Rossi и соавт. [11] также показали, что передне-задний размер левого предсердия служит предиктором обратного ремоделирования ЛЖ в условиях СРТ и позволяет выявить пациентов с высокой вероятностью достижения эффекта от данного метода лечения. Расширение левого предсердия обычно становится следствием аномально повышенного давления наполнения ЛЖ. Клиническое улучшение больных при применении СРТ отчасти обусловлено обратным ремоделированием левого предсердия и связанным с ним значительным снижением частоты возникновения фибрилляции предсердий и других наджелудочковых тахиаритмий [18].

Конечно-диастолический размер левого желудочка Наиболее специфичный маркер положительного ответа больных ХCH на применение устройств MCC - значение конечно-диастолического размера ЛЖ менее 7,8 см. Известно, что дилатация камер сердца, как правило, протекает параллельно с прогрессирующим истончением, фиброзированием и напряжением миокарда, которые, в свою очередь, сопряжены с уменьшением резервной сократительной способности кардиомиоцитов. Эти явления могут препятствовать достижению эффекта MCC у больных ХCH, что наиболее ожидаемо у пациентов с выраженно дилатированным ЛЖ.

Признаки фиброза миокарда левого желудочка по данным магнитно-резонансной томографии

У больных ХСН сопоставимое снижение систолической функции ЛЖ может выявляться как при минимальной, так и при выраженной картине рубцевания миокарда. Многочисленные исследования $[5,12,17]$ показали, что количество фиброзно-рубцового поражения миокарда и его топография могут быть важными факторами, определяющими способность пораженного миокарда реагировать на бивентрикулярную стимуляцию сердца при проведении СРТ. По нашим данным, при наличии МРТ-признаков фиброза в трех и более сегментах ЛЖ вероятность положительной реакции больных на применение устройств СРТ значимо снижается. Несмотря на то что большинство предшествующих работ $[5,17]$ показало снижение эффекта от применения СРТ исключительно в случаях заднебоковой локализации рубца, наши данные указывают на меньшую важность топографии рубцового поражения миокарда по сравнению с его площадью. По данным J.A. White и соавт. [24], фиброзно-рубцовое поражение сегментов межжелудочковой перегородки имеет большое значение для прогнозирования результатов СРТ у больных ХСН. В частности, у всех больных с распространенным (более 40\%) поражением межжелудочковой перегородки ЛЖ отмечалось отсутствие эффекта от применения СРТ. Наши данные косвенно подтверждают результаты работы О.В. Стукаловой и соавт. [12], установивших, что наиболее диагностически значимым признаком, ассоциированным с отсутствием эффекта СРТ у больных ХCH, выступает так называемый индекс фиброза - показатель, рассчитываемый на основании оценки общего количества пораженных сегментов ЛЖ, а также степени поражения каждого из них.

\section{Биомаркер NT-proBNP}

Важным результатом нашей работы стало выявление исходного значения концентрации NTproBNP в плазме крови более 3900 пг/мл в качестве предиктора невосприимчивости больных $\mathrm{XCH} \mathrm{к} \mathrm{применению} \mathrm{СРТ} \mathrm{(см.} \mathrm{табл.} \mathrm{2).} \mathrm{Однако} \mathrm{до-}$ стоверного влияния повышенных значений этого показателя на результаты применения МСС не обнаружено. Как известно, высокие значения биомаркера NT-proNBP указывают на значительное перенапряжение миокарда предсердий и желудочков, а также на общую тяжесть ХCH [12]. По-видимому, именно эти факторы могут препятствовать восстановлению сократимости миокарда ЛЖ в ответ на СРТ. Отметим: взаимосвязь между исходными значениями BNP/NT-proBNP и последующей реакцией больных на использование устройств СРТ ранее выявлялась лишь в части подобных исследований. Так, A.A. Shalaby и соавт. [8] показали зависимость исходов применения устройств СРТ у пациентов с ХCH от значений биомаркеров BNP и тропонина T. Напротив, С. Brouwers и соавт. [9] такой связи 
не обнаружили. Противоречивость результатов может быть следствием отсутствия учета других прогностически важных факторов, таких как, например, уровень sST2. Так, в работе S.U. Rehman и соавт. [25] у больных с декомпенсацией XCH повышение NT-proBNP имело отрицательное прогностическое значение в плане достижения результатов СРТ только в случаях одновременного повышения и уровня sST2. Подобная закономерность установлена и в нашем исследовании.

\section{Резюме основного результата исследования}

Единственным универсальным маркером отклика пациентов с ХСН и сниженной ФВ ЛЖ на применение обоих типов устройств были исходные значения sST2 $<50$ нг/мл для СРТ-Д, $<30$ нг/мл для MCC. Это указывает на потенциальную возможность повышения эффективности использования этих методов при их применении в более ранние сроки от дебюта заболевания, а также после достижения максимально возможной компенсации явлений ХCH у данной категории пациентов.

\section{Обсуждение основного результата исследования}

\section{Биомаркер sST2}

Одним из основных результатов нашей работы стало выявление биомаркера sST2 в качестве единственного универсального маркера эффективности использования СРТ и МСС у больных ХСН. Примечательно, что к отрицательным результатам использования обоих методов предрасполагали различные «отрезные» значения sST2: для СРТ - концентрация в плазме крови, превышающая 50 нг/мл, для МСС - более 28 нг/мл. Подобные расхождения в определении критически значимого порогового значения sST2 встречались в работах других авторов. В исследовании J. Lupón и соавт. [14] к развитию острой декомпенсации XCH предрасполагали значения sST2 более 49 нг/мл, тогда как по данным метаанализа баз данных 4268 пациентов со стабильной ХCH [15] прогностически неблагоприятными были признаны значения SST2 более 28 нг/мл.

Значения биомаркера sST2 отражают эффективность работы кардиопротективной сигнальной системы организма, использующей интерлейкин-33 для препятствования процессам ремоделирования сердца под действием различных патологических влияний. Эта система противостоит процессам гипертрофии и фиброзирования миокарда в ответ на перегрузку сердца объемом или давлением, его ишемию и воспаление, а также на гиперактивацию симпатической и ренин-ангиотензин-альдостероновой систем организма [26]. В свете результатов, полученных в настоящей работе, можно полагать, что эффективность применения СРТ и МСС, запускающих обратное ремоделирование сердца, во многом зависит не только от проявлений структурного поражения сердца (выраженности фиброза миокарда ЛЖ, размеров камер левых отделов сердца и др.), но и от запаса восстановительных резервов организма в целом, которые косвенно выражаются уровнем sST2 крови. Для достижения желаемых результатов применение СРТ и МСС должно быть своевременным, а именно длиться до того момента, когда сердечное ремоделирование приобретет необратимый характер. Полученные нами данные косвенно свидетельствуют о том, что перед имплантацией этих устройств пациентам с ХCH целесообразно достижение максимально возможного снижения концентрации sST2 в плазме крови с помощью лекарственных препаратов. Критический уровень для СРТ - менее 50 нг/мл, для МСС - менее 30 нг/мл.

\section{Ограничения исследования}

Существенным ограничением данной работы следует признать анализ относительно небольших выборок больных ХCH, особенно в подгруппе пациентов с MCC. Кроме того, sST2 (выявленный универсальный маркер ответа больных на применение устройств СРТ и МСС) может повышаться не только при сердечной патологии, но и при различных воспалительных заболеваниях, таких как ревматоидный артрит, бронхиальная астма, легочный фиброз, коллагенозы, злокачественные новообразования и язвенные колиты [27]. Это диктует необходимость планирования более масштабных исследований роли данного биомаркера в качестве предиктора ответа на применение немедикаментозных методов лечения $\mathrm{XCH}$ с тщательным отбором включаемых в них пациентов.

\section{Заключение}

Единственным универсальным маркером отклика пациентов с ХСН и сниженной ФВ ЛЖ на применение обоих типов устройств были исходные значения sST2 (<50 нг/мл для СРТ-Д, <30 нг/мл для МСC). Это указывает на потенциальную возможность повышения эффективности использования этих методов при их применении в более ранние сроки от дебюта заболевания, а также после достижения максимально возможной компенсации явлений ХCH у данной категории пациентов. (е) 


\section{Дополнительная информация}

\section{Финансирование}

Исследование проведено в рамках диссертационной работы А.Ж. Гаспарян «Значение мониторирования концентрации нейрогормональных маркеров ST2 и NT-proBNP у больных с сердечной недостаточностью, высоким риском развития внезапной сердечной смерти и различными имплантированными устройствами». Работа проведена без привлечения дополнительного финансирования со стороны третьих лиц.

\section{Конфликт интересов}

Авторы декларируют отсутствие явных и потенциальных конфликтов интересов, связанных с публикацией настоящей статьи.

\section{Участие авторов}

Н.Б. Шлевков - концепция и дизайн исследования, сбор и обработка материала, анализ полученных данных, написание текста; А.Ж. Гаспарян - концепция и дизайн исследования, сбор и обработка материала, анализ

\section{Литература / References}

1.Tomasoni $\mathrm{D}$, Adamo M, Lombardi CM, Metra M. Highlights in heart failure. ESC Heart Fail. 2019;6(6):1105-1127. doi: 10.1002/ehf2.12555.

2. O'Meara E, Prescott MF, Claggett B, Rouleau JL, Chiang LM, Solomon SD, Packer M, McMurray JJV, Zile MR. Independent Prognostic Value of Serum Soluble ST2 Measurements in Patients With Heart Failure and a Reduced Ejection Fraction in the PARADIGM-HF Trial (Prospective Comparison of ARNI With ACEI to Determine Impact on Global Mortality and Morbidity in Heart Failure). Circ Heart Fail. 2018;11(5):e004446. doi: 10.1161/CIRCHEARTFAILURE.117.004446.

3. Petrie MC, Verma S, Docherty KF, Inzucchi SE, Anand I, Belohlávek J, Böhm M, Chiang CE, Chopra VK, de Boer RA, Desai AS, Diez M, Drozdz J, Dukát A, Ge J, Howlett J, Katova T, Kitakaze M, Ljungman CEA, Merkely B, Nicolau JC, O'Meara E, Vinh PN, Schou M, Tereshchenko S, Køber L, Kosiborod MN, Langkilde AM, Martinez FA, Ponikowski P, Sabatine MS, Sjöstrand M, Solomon SD, Johanson P, Greasley PJ, Boulton D, Bengtsson O, Jhund PS, McMurray JJV. Effect of Dapagliflozin on Worsening Heart Failure and Cardiovascular Death in Patients With Heart Failure With and Without Diabetes. JAMA. 2020;323(14):1353-1368. doi: 10.1001/ jama.2020.1906.

4. Benstoem C, Kalvelage C, Breuer T, Heussen N, Marx G, Stoppe C, Brandenburg V. Ivabradine as adjuvant treatment for chronic heart failure. Cochrane Database Syst Rev. 2020;11:CD013004. doi: 10.1002/14651858. CD013004.pub2.

5. Daoulah A, Alsheikh-Ali AA, Al-Faifi SM, Ocheltree SR, Haq E, Asrar FM, Fathey A, Haneef AA, Al Mousily F, O el-S, Lotfi A. Cardiac resynchronization therapy in patients with postero-lateral scar by cardiac magnetic resonance: A systematic review and meta-analysis. J Elec- полученных данных, написание текста; А.А. Жамбеев набор клинического материала, анализ и интерпретация результатов исследования, написание текста; Х.Ф. Салами - набор клинического материала, анализ и интерпретация результатов исследования написание текста; Е.В. Гусева - анализ и интерпретация результатов исследования, написание текста; Г.С. Тарасовский - анализ и интерпретация результатов исследования, написание текста; Т.В. Шарф - анализ и интерпретация результатов исследования, написание текста; О.В. Стукалова - анализ и интерпретация результатов исследования, написание текста; Е.М. Гупало - набор клинического материала, написание текста; Н.А. Миронова - набор клинического материала, написание текста; А.А. Скворцов - разработка дизайна клинической части исследования, редактирование текста, утверждение итогового варианта текста рукописи; С.П. Голицын - разработка дизайна клинической части исследования, редактирование текста, утверждение итогового варианта текста рукописи. Все авторы прочли и одобрили финальную версию статьи перед публикацией, согласны нести ответственность за все аспекты работы и гарантируют, что ими надлежащим образом были рассмотрены и решены вопросы, связанные с точностью и добросовестностью всех частей работы.

\section{Благодарности}

Авторы статьи выражают благодарность к.м.н., врачу высшей категории, старшему научному сотруднику лаборатории интервенционных методов диагностики и лечения нарушений ритма, проводимости сердца и синкопальных состояний ФГБУ «НМИЦ кардиологии» Минздрава России В.Г. Киктеву, врачу ультразвуковой диагностики, младшему научному сотруднику отделения ультразвуковой диагностики ФГБУ «НМИЦ кардиологии» Минздрава России В.Н. Шитову, д.М.н., профессору, главному научному сотруднику отдела клинической лабораторной диагностики ФГБУ «НМИЦ кардиологии» Минздрава России В.П. Масенко. trocardiol. 2015;48(5):783-790. doi: 10.1016/j. jelectrocard.2015.06.012.

6. de Sá Junior IM, Pachón Mateos JC, Pachón Mateos JC, Vargas RNA. Evaluation of super-responders to cardiac resynchronization therapy in the presence of left bundle branch block and absence of scar in the posterolateral wall of the left ventricle. Am J Cardiovasc Dis. 2020;10(1): 17-27.

7. Hsu JC, Solomon SD, Bourgoun M, McNitt S, Goldenberg I, Klein H, Moss AJ, Foster E; MADIT-CRT Executive Committee. Predictors of super-response to cardiac resynchronization therapy and associated improvement in clinical outcome: the MADIT-CRT (multicenter automatic defibrillator implantation trial with cardiac resynchronization therapy) study. J Am Coll Cardiol. 2012;59(25):2366-2373. doi: 10.1016/j. jacc.2012.01.065.

8. Shalaby AA, Abraham WT, Fonarow GC, Bersohn MM, Gorcsan J 3rd, Lee LY, Halilovic J, Saba S, Maisel A, Singh JP, Sonel A, Kadish A. Association of BNP and Troponin Levels with Outcome among Cardiac Resynchronization Therapy Recipients. Pacing Clin Electrophysiol. 2015;38(5):581-590. doi: 10.1111/ pace.12610.

9. Brouwers $C$, Versteeg $H$, Meine $M$, Heijnen $C J$, Kavelaars AM, Pedersen SS, Mommersteeg PM. Association between brain natriuretic peptide, markers of inflammation and the objective and subjective response to cardiac resynchronization therapy. Brain Behav Immun. 2014;40:211218. doi: 10.1016/j.bbi.2014.03.017.

10. Bakos Z, Chatterjee NC, Reitan C, Singh JP, Borgquist R. Prediction of clinical outcome in patients treated with cardiac resynchronization therapy - the role of NT-ProBNP and a combined response score. BMC Cardiovasc Disord. 2018;18(1):70. doi: 10.1186/ s12872-018-0802-8.
11. Rossi L, Malagoli A, Piepoli M, Franchi F, Malavasi V, Casali E, Rusticali G, Villani GQ. Indexed maximal left atrial volume predicts response to cardiac resynchronization therapy. Int J Cardiol. 2013;168(4):3629-3633. doi: 10.1016/j. ijcard.2013.05.028.

12. Стукалова ОВ, Миронова НА, Уцумуева МД, Каштанова СЮ, Буторова ЕА, Шитов BН, Тарасовский ГС, Голицын СП, Терновой СК. Эффективность сердечной ресинхронизирующей терапии у пациентов с хронической сердечной недостаточностью различной этиологии в зависимости от структурного поражения миокарда по данным магнитно-резонансной томографии сердца с контрастированием. Российский кардиологический журнал. 2019;(12):22-32. doi: $\quad 10.15829 / 1560-4071-2019-12-22-32$ [Stukalova OV, Mironova NA, Utsumueva MD, Kashtanova SYu, Butorova EA, Shitov VN, Tarasovsky GS, Golitsyn SP, Ternovoy SK. [The effectiveness of cardiac resynchronization therapy in patients with chronic heart failure of various origin depending on the structural myocardial injury in cardiac magnetic resonance imaging]. Russian Journal of Cardiology. 2019;(12):22-32 Russian. doi: 10.15829/1560-4071-2019-12-2232.]

13. Скворцов АА, Нарусов ОЮ, Муксинова МД, Протасов ВН, Протасова ДЕ, Кузнецова ТВ Масенко ВП, Терещенко СН. Клиническоезначение серийного определения активности современных биомаркеров у больных после декомпенсации сердечной недостаточности: роль SST2 и NT-proBNP при длительном наблюдении. Кардиология. 2018;58(12S):2741. doi: 10.18087/cardio.2634. [Skvortsov AA, Narusov OYu, Muksinova MD, Protasov VN, Protasova DE, Kuznetsova TV, Masenko VP, Tereshchenko SN. [Clinical significance of serial biomarkers activity determination after acute 
heart failure decompensation: sST2 NT-proBNP role during long-term follow-up]. Kardiologiia [Cardiology]. 2018;58(12S):27-41. Russian. doi: 10.18087/cardio.2634.]

14. Lupón J, Gaggin HK, de Antonio M, Domingo M, Galán A, Zamora E, Vila J, Peñafiel J, Urrutia A, Ferrer E, Vallejo N, Januzzi JL, Bayes-Genis A. Biomarker-assist score for reverse remodeling prediction in heart failure: The ST2-R2 score. Int J Cardiol. 2015;184:337-343. doi: 10.1016/j. ijcard.2015.02.019.

15. Emdin M, Aimo A, Vergaro G, Bayes-Genis A, Lupón J, Latini R, Meessen J, Anand IS, Cohn JN, Gravning J, Gullestad L, Broch K, Ueland T, Nymo SH, Brunner-La Rocca HP, de Boer RA, Gaggin HK, Ripoli A, Passino C, Januzzi JL Jr. sST2 Predicts Outcome in Chronic Heart Failure Beyond NT-proBNP and High-Sensitivity Tropo- nin T. J Am Coll Cardiol. 2018;72(19):2309-2320. doi: 10.1016/j.jacc.2018.08.2165.

16. Министерство здравоохранения Российской Федерации. Хроническая сердечная недостаточность: Клинические рекомендации [Интернет]. 2020. Доступно на: https:// webmed.rirkutsk.ru/doc/pdf/fedhf.pdf. [Ministry of Health of the Russian Federation. [Chronic Heart Failure: Clinical guidelines] [Internet]. 2020. Available from: https://webmed.irkutsk. ru/doc/pdf/fedhf.pdf.]

17. Bleeker GB, Kaandorp TA, Lamb HJ, Boersma $E$, Steendijk $P$, de Roos $A$, van der Wall $E E_{\text {, }}$ Schalij MJ, Bax JJ. Effect of posterolateral scar tissue on clinical and echocardiographic improvement after cardiac resynchronization therapy. Circulation. 2006;113(7):969-976. doi: 10.1161/CIRCULATIONAHA.105.543678.
18. Brenyo A, Link MS, Barsheshet A, Moss AJ, Zareba W, Wang PJ, McNitt S, Huang D, Foster E, Estes M 3rd, Solomon SD, Goldenberg I. Cardiac resynchronization therapy reduces left atrial volume and the risk of atrial tachyarrhythmias in MADIT-CRT (Multicenter Automatic Defibrillator Implantation Trial with Cardiac Resynchronization Therapy). J Am Coll Cardiol. 2011;58(16): 1682-1689. doi: 10.1016/j.jacc.2011.07.020.

19. Bax JJ, Bleeker GB, Marwick TH, Molhoek SG, Boersma $E$, Steendijk $P$, van der Wall $E E$, Schalij MJ. Left ventricular dyssynchrony predicts response and prognosis after cardiac resynchronization therapy. J Am Coll Cardiol. 2004;44(9):1834-1840. doi: 10.1016/j. jacc.2004.08.016.

20.Xu E, Pereira MMA, Karakasilioti I, Theurich S, Al-Maarri M, Rappl G, Waisman A, Wunder-

\title{
Soluble suppression of tumorigenesis-2 (SST2), a new potential biomarker of response to cardiac resynchronization therapy and cardiac contractility modulation in patients with chronic heart failure
}

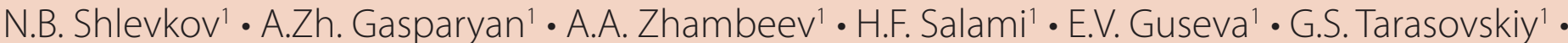 \\ T.V. Sharf • O.V. Stukalova' • E.M. Gupalo' • N.A. Mironova' • A.A. Skvortsov' • S.P. Golitsyn'
}

Background: According to numerous studies, from $30 \%$ to $50 \%$ of patients with chronic heart failure (CHF) are resistant to cardiac resynchronization therapy (CRT) and cardiac contractility modulation (CCM), despite their careful selection in accordance with current guidelines. It is of interest to study neurohormones characterizing myocardial (NT-proBNP) and fibrosis (SST2) as potential additional markers of CHF patients' "response" to CRT and CCM.

Aim: To evaluate the potential to use NT-proBNP and SST2 biomarkers in CHF patients combined with transthoracic echocardiography (Echo) and contrast magnetic resonance imaging (MRI) parameters of the heart to predict a positive response to CRT and CCM devices.

Materials and methods: The study included 51 patients ( 41 men, 10 women) aged $58 \pm 12$ years (26 to 79 years) with ischemic heart disease post acute myocardial infarction $(n=22)$ or non-ischemic cardiomyopathy $(n=29)$, left ventricle (LV) ejection fraction $(E F)<35 \%$, and CHF II-III NYHA functional class despite $\geq 3$ months of optimized medical therapy. The patients were assessed by serum biomarkers NT-proBNP and SST2 measurements, transthoracic Echo, and contrast-enhanced cardiac MRI. After the diagnostic assessment, CRT defibrillators (CRT-D) were implanted to 39 patients and CCM to 12 patients. After prospective follow-up of the patients for 18 to 24 months, predictors of the response to each device type were analyzed in univariate, multivariate, and ROC analysis.

Results: The response to CRT-D was found in 21 (54\%) patients, to CCM in 7 (58\%) patients. Multivariate analysis showed the following predictors of the response of patients to CRT-D were: 1) $\mathrm{sST} 2<50 \mathrm{ng} / \mathrm{mL}$, 2) NT-proBNP $<3900 \mathrm{pg} / \mathrm{mL}$, 3) $<3$ LV segments with fibrosis (by MRI) and 4) anteroposterior dimension of the left atrium $<4.8 \mathrm{~cm}$ (by Echo). Any 2 of these 4 characteristics made it possible to predict the response to CRT with an accuracy of $87 \%$ (sensitivity $90 \%$, specificity $83 \%)$. The predictors of the response to CCM were: 1) $\mathrm{sST} 2<30 \mathrm{ng} / \mathrm{ml}, 2) \mathrm{LV}$ end diastolic diameter $<78 \mathrm{~mm}$ (Echo), 3) age $<56$ years, 4) body mass index $<27 \mathrm{~kg} / \mathrm{m}^{2}$. Any 2 of these 4 characteristics predicted the positive response to CCM with an accuracy of $92 \%$ (sensitivity $86 \%$, specificity $100 \%$ ). Conclusion: The preoperative SST2 level was the only universal marker of the response to either CRT $(<50 \mathrm{ng} / \mathrm{mL})$ or CCM $(<30 \mathrm{ng} / \mathrm{mL})$ devices in CHF patients with reduced LVEF. The results indicate the potential for improved efficacy of these devices with their earlier implantation after the onset of the heart disease, as well as provided that maximal control CHF in these patients has been achieved.

Key words: biomarkers, NT-proBNP, sST2, chronic heart failure, cardiac resynchronization therapy, cardiac contractility modulation, prognosis

For citation: Shlevkov NB, Gasparyan AZh, Zhambeev AA, Salami HF, Guseva EV, Tarasovskiy GS, Sharf TV, Stukalova OV, Gupalo EM, Mironova NA, Skvortsov AA, Golitsyn SP. Soluble suppression of tumorigenesis-2 (SST2), a new potential biomarker of response to cardiac resynchronization therapy and cardiac contractility modulation in patients with chronic heart failure. Almanac of Clinical Medicine. 2021:49(2):99-112. doi: 10.18786/2072-0505-202149-025

Received 22 April 2021; revised 27 April 2021; accepted 30 April 2021; published online 26 May 2021 
lich FT, Brüning JC. Temporal and tissue-specific requirements for T-lymphocyte IL-6 signalling in obesity-associated inflammation and insulin resistance. Nat Commun. 2017;8:14803. doi: 10.1038/ncomms14803.

21.Dobrowolski P, Prejbisz A, Klisiewicz A, Florczak E, Rybicka J, Januszewicz A, Hoffman P. Determinants of concentric left ventricular hypertrophy in patients with resistant hypertension: RESIST-POL study. Hypertens Res. 2015;38(8):545-550. doi: 10.1038/hr.2015.39.

22. Гиоева ЗМ, Богданов АР, Залетова ТС, Богданова АА. Ожирение как фактор риска развития хронической сердечной недостаточности (литературный обзор). Доктор. Py. 2017;10(139):21-25. [Gioeva ZM, Bogdanov AR, Zaletova TS, Bogdanova AA. [Obesity as

\section{Funding}

The study was performed as a part of the thesis of A.Zh. Gasparyan "The value of SST2 and NT-proBNP neurohormonal marker monitoring in the patients with heart failure, high risk of sudden cardiac death and various implanted devices". The study was conducted without any additional financial support from any third parties.

\section{Conflict of interests}

The authors declare no conflict of interests.

\section{Authors' contributions}

N.B. Shlevkov, the study concept and design, data collection and management, data analysis, text writing; A.Zh. Gasparyan, the study concept and design, data collection and management, data analysis, text writing; A.A. Zhambeev, clinical data collection, analysis and interpretation of the results, text writing; H.F. Salami, clinical data collection, analysis and interpretation of the results, text writing; E.V. Guseva, analysis and interpretation of the results, text writing; G.S. Tarasovskiy, analysis and interpretation of the results, text writing; T.V. Sharf, analysis and interpretation of the results, text writing; O.V. Stukalova, analysis and interpretation of the results, text writing; E.M. Gupalo, clinical data collection, text writing; N.A. Mironova, clinical data collection, text writing; A.A. Skvortsov, design of the clinical part of the study, text editing, approval of the final version of the manuscript; S.P. Golitsyn, design of the clinical part of the study, text editing, approval of the final version of the manuscript. All the authors have read and approved the final version of the manuscript before submission, agreed to be accountable for all aspects of the work in ensuring that questions related to the accuracy or integrity of any part of the work are appropriately investigated and resolved.

\section{Acknowledgements}

The authors would like to acknowledge V.G. Kiktev, MD, $\mathrm{PhD}$, Senior Research Fellow, High Qualification Certificate, Laboratory of Interventional Diagnosis and Treatment of Rhythm, Conduction Disorders and Syncopal Episodes; V.N. Shitov, Junior Research Fellow, Specialist in Ultrasound Assessment, Department of Diagnostic Medical Sonography; V.P. Masenko, MD, PhD, Professor, Chief Research Fellow, Department of Clinical Laboratory Diagnostics (all in the National Medical Research Cardiology Center). a risk factor for chronic heart failure: a review of the literature]. Doctor.Ru. 2017;10(139):21-25. Russian.]

23. Seko Y, Kato T, Morimoto T, Yaku H, Inuzuka Y, Tamaki Y, Ozasa N, Shiba M, Yamamoto E, Yoshikawa Y, Yamashita Y, Kitai T, Taniguchi R, Iguchi M, Nagao K, Kawai T, Komasa A, Nishikawa R, Kawase Y, Morinaga T, Toyofuku M, Furukawa Y, Ando K, Kadota K, Sato Y, Kuwahara K, Kimura T. Association between body mass index and prognosis of patients hospitalized with heart failure. Sci Rep. 2020;10(1):16663. doi: 10.1038/s41598-020-73640-w.

24. White JA, Yee R, Yuan X, Krahn A, Skanes A, Parker M, Klein G, Drangova M. Delayed enhancement magnetic resonance imaging predicts response to cardiac resynchronization therapy in patients with intraventricular dyssynchrony.
J Am Coll Cardiol. 2006;48(10):1953-1960. doi: 10.1016/j.jacc.2006.07.046.21.

25. Rehman SU, Mueller T, Januzzi JL Jr. Characteristics of the novel interleukin family biomarker ST2 in patients with acute heart failure. J Am Coll Cardiol. 2008;52(18):1458-1465. doi: 10.1016/j.jacc.2008.07.042.

26. Sanada S, Hakuno D, Higgins LJ, Schreiter ER, McKenzie AN, Lee RT. IL-33 and ST2 comprise a critical biomechanically induced and cardioprotective signaling system. J Clin Invest. 2007;117(6):1538-1549. doi: 10.1172/ JCI30634.

27. Kuroiwa K, Arai T, Okazaki H, Minota S, Tominaga S. Identification of human ST2 protein in the sera of patients with autoimmune diseases. Biochem Biophys Res Commun. 2001;284(5): 1104-1108. doi: 10.1006/bbrc.2001.5090.
Nikolay B. Shlevkov - MD, PhD, Leading Research Fellow, Laboratory of Interventional Methods for Diagnostics and Treatment of Rhythm Disorders, Cardiac Conduction and Syncope, Department of Clinical Electrophysiology and X-ray Surgical Methods for Treatment of Heart Rhythm Disorders, Research Institute of Cardiology'; ORCID: https:// orcid.org/0000-0003-3956-1860

$\triangle$ 15a 3-ya Cherepkovskaya ul., Moscow, 121552, Russian Federation. Tel.: +7 (495) 1504419.

E-mail: nik.shlevkov@inbox.ru

Armenui Zh. Gasparyan - Postgraduate Student, Department of Clinical Electrophysiology and X-ray Surgical Methods for Treatment of Heart Rhythm Disorders, Research Institute of Cardiology'; ORCID: https://orcid.org/0000-0001-9984-6505.

E-mail: doctor_gasparyan@inbox.ru

Azamat A. Zhambeev - Postgraduate Student, Department of Clinical Electrophysiology and X-ray Surgical Methods for Treatment of Heart Rhythm Disorders, Research Institute of Cardiology'; ORCID: https://orcid.org/0000-0002-3550-6111.

E-mail: azhambeev@yandex.ru

Hussein F. Salami - MD, Cardiovascular Surgeon, Clinical Department No. 7a, Research Institute of Cardiology'; ORCID: https://orcid.org/0000-00019751-7767. E-mail: hussein_salami@mail.ru

Elena V. Guseva - Postgraduate Student, Department of Clinical Electrophysiology and X-ray Surgical Methods for Treatment of Heart Rhythm Disorders, Research Institute of Cardiology'; ORCID: https://orcid.org/0000-0001-6500-3649.

E-mail: gev1994@list.ru
Gennady S. Tarasovskiy - MD, Cardiologist, Clinical Department No. 7a, Research Institute of Cardiology'; ORCID: https://orcid.org/0000-00022143-8912. E-mail: gena80@yandex.ru

Tatiana V. Sharf - Research Fellow, Research Institute of Experimental Cardiology'; ORCID: https:// orcid.org/0000-0003-1993-9264.

E-mail: tsharf@rambler.ru

Olga V. Stukalova - MD, PhD, Senior Research Fellow, Department of Tomography, Research Institute of Cardiology'; ORCID: https://orcid. org/0000-0001-8377-2388.

E-mail: olgastukalova@mail.ru

Elena M. Gupalo - MD, PhD, Research Fellow, Department of Clinical Electrophysiology and X-ray Surgical Methods for Treatment of Heart Rhythm Disorders, Research Institute of Cardiology'; ORCID: https://orcid.org/0000-0002-0063-5474.

E-mail: eleno4ka_g@mail.ru

Nataliya A. Mironova - MD, PhD, Senior Research Fellow, Department of Clinical Electrophysiology and X-ray Surgical Methods for Treatment of Heart Rhythm Disorders, Research Institute of Cardiology'; ORCID: https://orcid.org/0000-0002-0063-5474. E-mail: mirona01@mail.ru

Andrey A. Skvortsov - MD, PhD, Leading Research Fellow, Department of Myocardial Diseases and Heart Failure, Research Institute of Cardiology'; ORCID: https://orcid.org/0000-0003-2712-927X. E-mail: skvortsov00@yandex.ru

Sergey P. Golitsyn - MD, PhD, Professor, Head of Department of Clinical Electrophysiology and X-ray Surgical Methods for Treatment of Heart Rhythm Disorders, Research Institute of Cardiology'; ORCID: https://orcid.org/0000-0001-9913-9974.

E-mail: golitsyn@mail.ru 